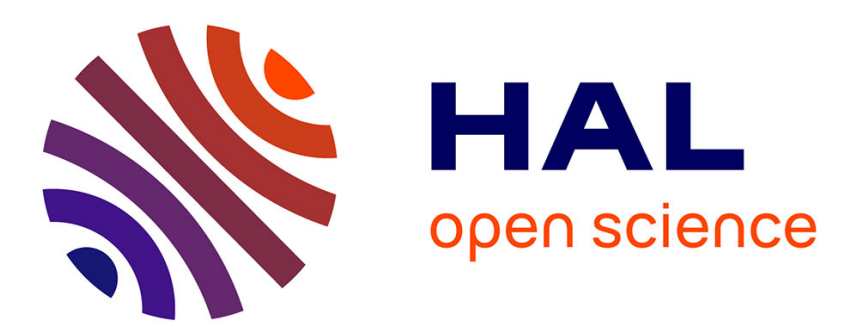

\title{
Control of the Size of Cobalt Ferrite Nanoparticles: Synthesis and Properties
}

\author{
M. Pileni, N. Moumen, J. Hochepied, P. Bonville, P. Veillet
}

\section{To cite this version:}

M. Pileni, N. Moumen, J. Hochepied, P. Bonville, P. Veillet. Control of the Size of Cobalt Ferrite Nanoparticles: Synthesis and Properties. Journal de Physique IV Proceedings, 1997, 07 (C1), pp.C1505-C1-508. 10.1051/jp4:19971207 . jpa-00254858

\section{HAL Id: jpa-00254858 https://hal.science/jpa-00254858}

Submitted on 1 Jan 1997

HAL is a multi-disciplinary open access archive for the deposit and dissemination of scientific research documents, whether they are published or not. The documents may come from teaching and research institutions in France or abroad, or from public or private research centers.
L'archive ouverte pluridisciplinaire HAL, est destinée au dépôt et à la diffusion de documents scientifiques de niveau recherche, publiés ou non, émanant des établissements d'enseignement et de recherche français ou étrangers, des laboratoires publics ou privés. 


\title{
Control of the Size of Cobalt Ferrite Nanoparticles: Synthesis and Properties
}

\author{
M.P. Pileni****, N. Moumen*, J.F. Hochepied*, P. Bonville*** and P. Veillet**** \\ * Laboratoire SRSI, URA 1662 du CNRS, Université P. et M. Curie (Paris VI), BP. 52, 4 Place Jussieu, \\ 75231 Paris cedex 05, France \\ ** C.E.A. - C.E. Saclay, DRECAM-S.C.M, 91191 Gif sur Yvette cedex, France \\ *** C.E.A. - C.E. Saclay, DRECAM-S.P.E.C., 91191 Gif sur Yvette cedex, France \\ **** Institut d'Electronique Fondamentale URA 22 du CNRS, Centre Universitaire d'Orsay, Bât. 220, \\ 91405 Orsay cedex, France
}

\begin{abstract}
The preparation of a fluid of cobalt ferrite particles having a size varying from 2 to $5 \mathrm{~nm}$ is described. This has been achieved by using functionalized surfactants. The size of cobalt ferrite particles decreases when the total reactant concentration decreases. The magnetic properties are described with magnetization curves and ${ }^{57} \mathrm{Fe}$ mössbauer spectroscopy. It is demonstrated that these particles are characterized by a superparamagnetic behavior.
\end{abstract}

\section{INTRODUCTION}

Many investigations have been performed on particles having a size ranging from 10 to 30nm. A behavior called superparamagnetism has been found[1].Moreoever, small magnetic particles have surface properties that differ from the core. The elucidation of these differences is particularly difficult. The surface morphology, which depends on the preparation technique, may vary. Passivation[2] may introduce more than one phase. Interparticle interactions[3], especially magnetic ones, may be important. The coating at the surface may change the intrinsic surface properties[1]. The study of magnetic materials having sizes smaller than 10nm increases extensively[4]. Recently Davies et al. produced cobalt ferrite particles characterized by an average size equal to $3 \mathrm{~nm}$. In all these cases, syntheses have been performed by using very high concentrations of metallic salts and basis. The solutions were heated at relatively high temperature (close to $100^{\circ} \mathrm{C}$ ). The control of the size was obtained by changing the experimental conditions such as $\mathrm{pH}$, ionic strength, complexation etc....

In the present paper we propose a new technique to synthetize nanosized cobalt ferrite particles. A gradual control of the size is obtained. From magnetization measurements and ${ }^{57} \mathrm{Fe}$ mössbauer spectroscopy we have observed a transition from cubic to axial anisotropy and a strong increase of the anisotropy constant with the decreasing particle size.

\section{SYNTHESIS OF $\mathrm{CoFe}_{2} \mathrm{O}_{4}$ NANOSIZED PARTICLES}

\subsection{Synthesis and characterization.}

Aqueous methylamine, $\mathrm{CH}_{3} \mathrm{NH}_{3} \mathrm{OH}$, is added to a mixed micellar solution formed by $\mathrm{Co}(\mathrm{DS})_{2}$ and $\mathrm{Fe}(\mathrm{DS})_{2}$ surfactants. Cobalt (II) and Iron(II) dodecyl sulfate, $\mathrm{Co}(\mathrm{DS})_{2}$, and $\mathrm{Fe}(\mathrm{DS})_{2}$ were made as described elsewhere[5].The solution is stirred during two hours at room temperature and a magnetic precipitate appears. The supernatant is removed and replaced by pure bulk aqueous phase. The precipitate is redispersed and a brown magnetic suspension is obtained. It is usually called magnetic fluid. The percentage of surfactant remaining in solution is less than $0.1 \%$ in weight. Electron diffractogram patterns of the powder show a good agreement with the intense peaks listed for cobalt ferrite, $\mathrm{Co}(\mathrm{II}) \mathrm{Fe}(\mathrm{III})_{2} \mathrm{O}_{4}$, in standard reference tables. This indicates that the particles formed by using a micellar solution have the inverse spinel crystalline structure, as in the bulk phase. Formation of cobalt ferrite, $\mathrm{CoFe}_{2} \mathrm{O}_{4}$, is confirmed by $\mathrm{X}$ rays diffraction spectra. A fit of the experimental data yields a value of lattice

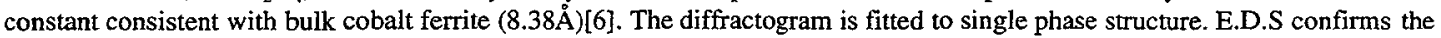
relative ratio of cobalt and iron elements in the cobalt ferrite particles (the percentage of the iron and cobalt elements are found equal to $65.6 \%$ and $34.3 \%$ respectively).

\subsection{Size control.}

Syntheses have been performed by increasing the $\mathrm{Fe}(\mathrm{DS})_{2}$ concentration, from $6.5 .10^{-3} \mathrm{M}$ to $2.6 .10^{-2} \mathrm{M}$, keeping the $\left[\mathrm{Co}(\mathrm{DS})_{2}\right] /\left[\mathrm{Fe}(\mathrm{DS})_{2}\right]$ and $\left[\mathrm{Fe}(\mathrm{DS})_{2}\right] /\left[\mathrm{CH}_{3} \mathrm{NH}_{3} \mathrm{OH}\right]$ ratios equal to 0.325 and $1.3 .10^{-2}$ respectively (fig.1). 
The size of the particles is determined by T.E.M. and by S.A.X.S. : using a Porod plot, I.q ${ }^{+}$versus q. the average diameter can be determined from the value of $q$ at the maximum and/or the minimum. Both S.A.X.S. and T.E.VI. data are in a good agreement (Table 1). We observe an increase in the particle size with the increasing Fe(DS) z concentration.

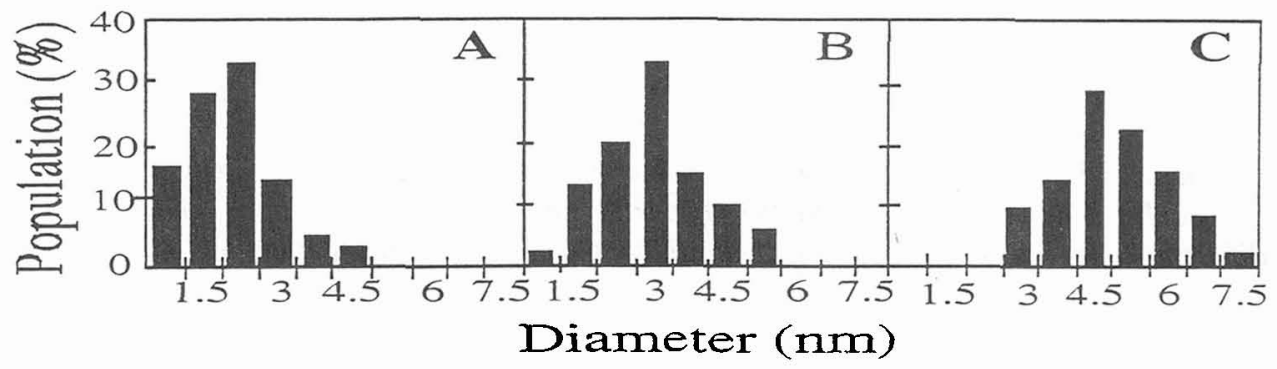

Fig.1: Histograms of magnetic fluid made at various surfactant concentrations keeping $[\mathrm{Co}(\mathrm{DS}) 2] /[\mathrm{Fe}(\mathrm{DS}) 2]=1) .325$. [Co(DS)2] $[\mathrm{NH} 2 \mathrm{CH} 3]=1.3 .10-2$. $[\mathrm{Fe}(\mathrm{DS}) 2]=6.5 \quad 10-3 \mathrm{M}(\mathrm{A}),[\mathrm{Fe}(\mathrm{DS}) 2]=1.3 \quad 10-2 \mathrm{M}(\mathrm{B}),[\mathrm{Fe}(\mathrm{DS}) 2]=2.610-2 \mathrm{M}$ (C).

\section{MAGNETIC PROPERTIES}

The magnetization curves (S.Q.U.I.D. magnetometer) of particles having an average diameter equal to 2 , 3 and 5 nm respectively show at $200 \mathrm{~K}$ a superparamagnetic behavior as expected for nanoscale dimension of the particles. The magnetic size of the particle can be deduced from simulation of Langevin relationship assuming a log normal size distribution[7]. $A$ good agreement between the size determined by T.E.M, and from magnetization curve is observed (Table 1).

The magnetic field needed to reach the saturation magnetization depends on the size of the particles. For particles having an average size equal to $2 \mathrm{~nm}$ and $3 \mathrm{~nm}$, the saturation is not reached even at $4 \mathrm{~T}$ whereas it is observed with $5 \mathrm{~nm}$ particles. The saturation magnetization, deduced from zero extrapolation of $\mathrm{M}$ vs $1 / \mathrm{H}$, decreases with the decrease in the particle size (Table l). The magnetic particles are frozen in zero field at $10 \mathrm{~K}$. Figure 2 shows the presence of hysteresis and an increase in the coercitivity with the increasing particle size (Table 1). Preliminary experiments performed at higher fields (up to 14T) show that saturation cannot be reached for particles having an average diameter equal to 2 and $3 \mathrm{~nm}$ respectively. In that case. the saturation magnetization is evaluated as described before after deducing a linear differential susceptibility and the ratio $\mathrm{Mr} / \mathrm{Ms}$ is roughiy equal to 0.5 .
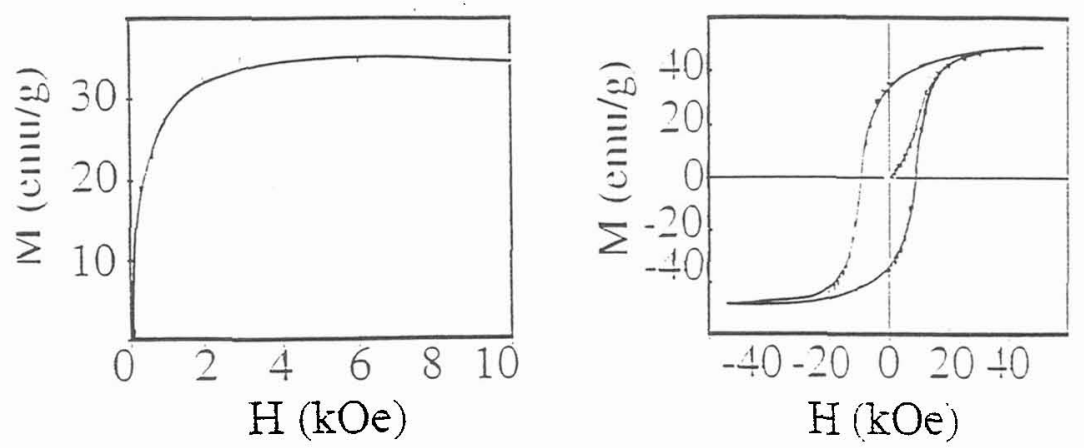

Fig.2 Magnetization curves for 5nm diameter particles at $300 \mathrm{~K}$ (left) and $10 \mathrm{~K}$ (right).

Table 1 shows a decrease in the saturation magnetization with the decrease in the particle size. Even for the larger particles ( $5 \mathrm{~nm}$ diameter), the saturation magnetization is less than the bulk value. This could be explained by an increase in noncollinearity structure when the particle size decreases.

The ratio of the remanence to saturation magnetization, $\mathrm{Mr} / \mathrm{Ms}$, deduced from the magnetization curve decreases with the decrease in particle size (Table 1). The reduced remanence, Mr/Ms, depends on the magnetocrystalline anisotropy constant. the median diameter and the standard deviation of the system[8]. For random distribution of easy magnetic axes of particles with cubic magnetocrystalline anisotropy, the reduced remanence is expected to be equal to 0.83 at $0 \mathrm{~K}$. For particies having $5 \mathrm{~nm}$ as an average diameter. Table 1 shows a $\mathrm{Mr} / \mathrm{Ms}$ ratio equal to 0.74 at $10 \mathrm{~K}$. The large remanence and coercitivity values and the remanence to saturation magnetization ratio indicate that $5 \mathrm{~nm}$ particles consist of randomly oriented equiaxial particles with cubic magnetocrystalline anisotropy[9]. The progressive decrease of $\mathrm{Mr} / \mathrm{Ms}$ ratio with the decrease in the particle size given on Table 1 could be explained as a progressive change of magnetocrystalline anisotropy from cubic to axial structure. The source of anisotropy might differ in uitrafine particle from the bulk material. 
Mössbauer spectroscopy performed at various temperatures and sizes confirms the superparamagnetic behavior of the particles: we observe a transition from a sextet at low temperature to a quadrupolar doublet at high temperature (fig.3). From simulation of Mössbauer spectra at various temperatures the transition from cubic $(5 \mathrm{~nm})$ to axial (2 and $3 \mathrm{~nm})$ anisotropy is confirmed[10].

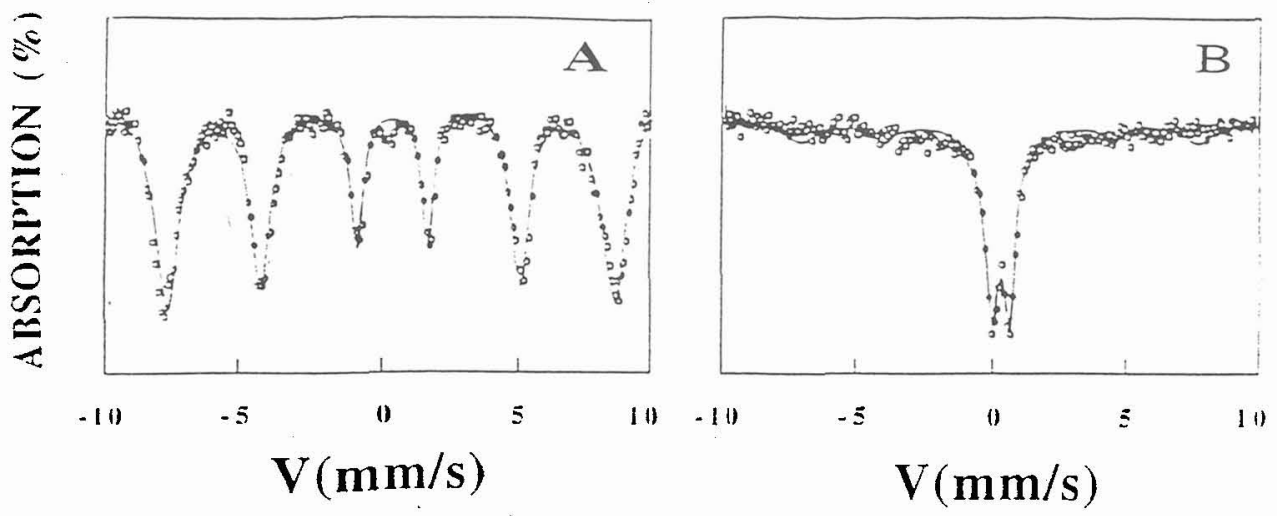

Fig.3 Mössbauer spectra of $3 \mathrm{~nm}$ particles at $4.2 \mathrm{~K}(\mathrm{~A})$ and $180 \mathrm{~K}(\mathrm{~B})$.

The samples are cooled in zero field to $10 \mathrm{~K}$. Figure 4 shows the magnetization measured as a function of temperature in a 1000 field. We have assimilated the temperature of the ZFC peak to the blocking temperature.

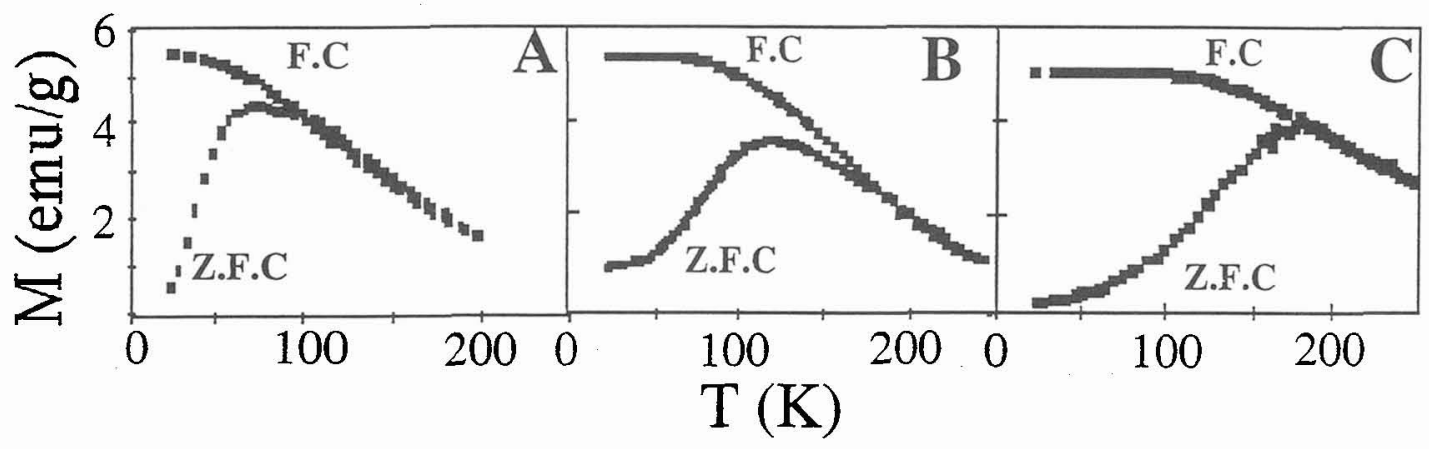

Fig. 4 : Zero Field Cooled (ZFC) and Field Cooled (FC) magnetization versus temperature in a field of 100 Oe for $2 \mathrm{~nm}(\mathrm{~A})$, 3nm (B) and $5 \mathrm{~nm}(\mathrm{C})$ cobalt ferrite particles in fluid. Volume fraction $=1 \%$.

Table 1: Average diameter of the particles deduced from T.E.M. DT.E.M(nm), by SAXS, DSAXS(nm), by X ray diffraction. DXR(nm) and from simulation in magnetic fluid, $\mathrm{DMF}(\mathrm{nm})$. The polydispersity in size determined by TEM, $\sigma$ T.E.M, and from simulation, $\sigma \mathrm{MF}$ and $\sigma \mathrm{MD}$. Variation of the saturation magnetization at $200 \mathrm{~K}\left(\mathrm{Ms}_{200}\right)$ and $10 \mathrm{~K}\left(\mathrm{Ms}_{10}\right)$, the ratio of the remanence and saturation magnetization at $10 \mathrm{~K}, \mathrm{Mr}_{10} / \mathrm{Ms}_{10}$, the coercitivity at $10 \mathrm{~K}, \mathrm{Hc}(\mathrm{kOe})$, the susceptibility at $200 \mathrm{~K} \chi_{200}$ and the anisotropy constant. $\mathrm{K}_{\mathrm{A}}$.

\begin{tabular}{|c|c|c|c|}
\hline$\left[\mathrm{Fe}(\mathrm{DS})_{2}\right]\left(10^{-2} \mathrm{M}\right)$ & 0.65 & 1.3 & 2.6 \\
\hline DT.E.M(nm) & 2 & 3 & 5 \\
\hline DSAXS(nm) & 2 & 3 & 4.2 \\
\hline $\mathrm{DXR}(\mathrm{nm})$ & 2.3 & 3.2 & 5.4 \\
\hline $\mathrm{DMF}(\mathrm{nm})$ & 2 & 3 & 4.2 \\
\hline бT.E.M (\%) & 37 & 36 & 23 \\
\hline$\sigma M F(\%)$ & 42 & 40 & 35 \\
\hline $\mathrm{Ms}_{200}(\mathrm{emu} / \mathrm{g})$ & 14 & 22 & 35 \\
\hline $\mathrm{Ms}_{10}(\mathrm{emu} / \mathrm{g})$ & 23 & 31 & 50 \\
\hline $\mathrm{Ms}_{200} / \mathrm{Ms}_{10}$ & 0.60 & 0.71 & 0.70 \\
\hline $\mathrm{Mr}_{10} / \mathrm{Ms}_{10}$ & 0.31 & 0.43 & 0.74 \\
\hline $\mathrm{Hc}(\mathrm{kOe})$ & 5 & 7.5 & 9 \\
\hline$\chi_{200}\left(10^{-4} \mathrm{emu} / \mathrm{g} / \mathrm{Oe}\right)$ & 2 & 2.4 & 4 \\
\hline $\mathrm{K}_{\mathrm{A}} \cdot\left(10^{-7} \mathrm{erg} \cdot \mathrm{cm}^{-3}\right)$ & 7 & 3 & 1 \\
\hline
\end{tabular}


As expected, the blocking temperature increases with the particle size (Table 1). From it, the anisotropy constant is dectuced. We observe a decrease in the anisotropy constant with the particle size. It is larger than the bulk value of cobalt ferrite material. The anisotropy constant, $\mathrm{K}_{\mathrm{A}}$, is the sum of several terms taking into account the magnetocrystalline anisotropy, the shape and the surface of the particles and the interactions between particles[11]. As expected, Figure 4 shows an increase in the blocking temperature with the increasing particle size. The anisotropy constant, determined from zero field cooling curve, is shown on Table 1. Whatever the size is, the anisotropy constant is always much larger than that obtained for bulk material. The increase in the anisotropy constant with the decreasing particle size could be attributed to an increase of the surface anisotropy. The comparison between the change of $\mathrm{Mr} / \mathrm{Ms}$ and $\mathrm{K}_{\mathrm{A}}$ with the particle size indicates that $\mathrm{K}_{\mathrm{A}}$ increases much drastically than $\mathrm{Mr} / \mathrm{Ms}$ with the decreasing particle size. $K_{A}$ contains anisotropy terms such as surface and shape anisotropies and interactions between particles. From T.E.M. no change in the shape of the particles can be observed. The good agreement between the particle size determined by T.E.M and from simulation of Langevin curve indicates that the interactions between particles are negligible. Therefore, it is reasonable to conclude that the strong increase in the anisotropy with the decrease in size is due to surface anisotropy.

\section{Conclusion}

For the first time, the preparation of cobalt ferrite particles having a size varying from 2 to $5 \mathrm{~nm}$ is described. This has been achieved by using functionalized surfactants. The size of the cobalt ferrite particles decreases when the total reactant concentration decreases and when the sodium dodecyl sulfate concentration increases. It is now possible to make various sizes of cobalt ferrite particles with $30 \%$ polydispersity in size distribution. These particles are characterized by a superparamagnetic behavior. The decrease in the saturation magnetization with the particle size is explained in term of an increase in the noncollinear structure at the interface. For $5 \mathrm{~nm}$ particles a cubic magnetocrystalline anisotropy is observed. By decreasing the size of the particles the surface anisotropy strongly increases and a transition from cubic to axial anisotropy may appear.

\section{references}

[1] Norrish, A.H., (1992), In "Studies of Magnetic Properties of Fine Particles and their relevance to Materials Science" $p$ 181, Editors Dormann, J.L. and Fiorani, D. Elsevier Science Publishers

[2] Gangopadhyay, S., Hadjipanayis, G.C., Sorensen, C.M. and Klabunde, K.J., (1993), IEEE Trans.Mag., 29, 2619

[3] Ferré,R., Barbara, B., Fruchart, D.and Wolfers, P., (1995), J.Mag. Mag.Mat., 140, 385

[4] Nakatsuka, K. and Jeyadevan, B., (1994), I.E.E.E. Trans.Magn., 30, 4671 Rozenberg, A.S., Aleksandrova, E.I., Dzhardimalieva, G.I., Kir'yakov, N.V., Chizhov, P.E., Petinov, V.I. and Pomogailo, A.D., (1995), Russian Chem.Bull., 44, 858

Vandenberghe, R.E., Vandenberghe, R, De Grave, E. and Robbrecht, G., (1980), J.Mag.Mag.Mater., 15, 1117

Sato, T., Jijima, T., Seki, M., Inagaki, J., (1987), J.Magn.Magn.Mater., 65, 252

Davies, K.J., Wells, S. and Charles, S.W., (1993), J.Magn.Magn.Mater., 122, 24

[5] Moumen, N. and Pileni M.P., (1995), J.Phys.Chem., 100, 1867

[6] J. Smit, and H. P. J. Wijn; Advan. Electron. Electron Phys.6 (1954) 83.

[7] Charles,S.W and Popplewell,J.; "Ferromagnetic Materials, Vol.2, Ed. Wohlfarth, Publisher Publ.Northholland Publishing Company Amsterdam, New York, Orford (1982)

[8] Charles,S.W; Chandrasekhar, R.; O'Grady,K. and Walker, M.;.Appl. PHys.; 1988, 64, 5840

[9] "Magnetism and Mettallurgy Berkowtiz, A.E and Kneller, E editors, Academic Press Publ., (1969), vol 1 chap. 8.

[10] Moumen N., Bonville P. and Pileni M.P.,(1996), J. Phys. Chem. (in press)

[11] Dormann, J.L.; Revue Phys.Appl.; 1981, 16, 275 